\title{
Fucoidan Protects Human Skin Fibroblast Cell Line HS68 Against $\gamma$ - Radiation-Induced Damage
}

\author{
Keyong Ho Lee ${ }^{\mathrm{a}}$, Sang woo Bae ${ }^{\mathrm{b}}$, Choa-Hyung Cho ${ }^{\mathrm{c}}$ and Ki Hyeong Rhee, \\ ${ }^{a}$ Kolon Life Science, Inc., Yongin 446-797, Korea \\ ${ }^{b}$ Korea Institute of radiological and Medical sciences Laboratory of Modulation of Radiobiological responses, Seoul \\ 139-706, Korea \\ ${ }^{c}$ College of Environmental \& Bioresource Sciences, Chonbuk National University, Iksan 570-752 Korea \\ ${ }^{d}$ College of Industrial Sciences, Kongju National University, Yesan, 340-702, Korea
}

\begin{abstract}
Fucoidan is a sulfated polysaccharide purified from brown algae including, Fucus vesiculosus and Fucus vesiculosus and Laminaria japonica. It has a variety of biological effects including antioxidant and antitumor activity. In this study, we investigated the radioprotective effects of fucoidan on normal human newborn foreskin fibroblast cell line HS68. To evaluate the effects of fucoidan, we assayed cell viability in vitro and change of blood cells such as thrombocytes, erythrocytes, leukocytes and hematocrit with radiation. In a viability assay, fucoidan increased dose-dependently the recovery of radiation-induced damage by $8 \mathrm{~Gy}$ at all tested dose $(10,50$ and $100 \mu \mathrm{g} / \mathrm{ml})$. The survival rate of HS68 cells by pre-treatment with fucoidan was increased by 2 times more than it's compared with untreated cells. Furthermore, fucoidan protected the change of blood cells as follows; the thrombocyte of the irradiated controls had fallen to $35 \%$ compared with the initial values, the thrombocyte counts in fucoidan pre-treated group was recovered to $49 \%$ at the day 14 . The Hematocrit level of fucoidan pre-treated group showed the recovery activity by $72 \%$ at the day 14 , while hematocrit level of irradiated control without fucoidan fell to $61 \%$. In case of erythrocyte level, the radiated controls was consistently maintained by the end of experiment at the range of $60 \sim 70 \%$, on the other hand, the erythrocyte counts of fucoidan pretreated group gently increased the level of erythrocyte at the range of $82 \sim 90 \%$. These results may provide valuable and useful information in the field of radio-protection.
\end{abstract}

\section{INTRODUCTION}

Of the several chemicals considered for radio-protection, WR-2721 (S-2-(3-aminopropylamino) phosphorothioic acid), a derivative of cysteamine, has been found to be the most effective in protecting mammals [1-3]. Other synthetic compounds were MPG (2-mercaptopropionyglycine), zinc aspirate, cysteamine and aminothiol. Unfortunately, these compounds showed several side effects [4,5]. Among these compounds, difficulties were encountered when administering WR-2721 to humans, who experienced adverse toxic effects such as hypertension, nausea and allergy when exposed to the drug [6]. Recently, fucoidan is being studied widely due to potential antitumor, antiviral, and antiinflammatory activities [7], and also has a UV protection activity on skin [8]. We found that fucoidan potentially have a radio-protection effect through the screening for radioprotector that has low toxicity from natural products. In this paper, we report the reduction of the damage against normal human lung fibroblast, and the hematological change in mice.

*Address correspondence to this author at the College of Industrial Sciences, Kongju National University, Yesan 340-702, Korea; Tel: +82-31280-8753; Fax: +82-31-280-8760; E-mail: howard@kongju.ac.kr

\section{MATERIALS AND METHODS}

\section{Animal Care}

Five male Blab/c mice (SLC, Japan) weighing 20-22g were housed in a cage at standard condition $\left(21-23{ }^{\circ} \mathrm{C}\right.$, controlled humidity, $12 \mathrm{hr}$ light/dark cycle). The animals were allowed to acclimate for one week prior to initiation of drug treatment. The Animal Care and Use Committees at the Institute of Kolon Life Science, Inc, approved the experimental procedures.

\section{Cell Culture}

The normal human newborn foreskin fibroblast cell line, HS68 cell (ATCC CRL 1635), was obtained from American Type Culture Collection (Rockville, MD, USA). HS68 cells were plated in T-25 flask and grown in Dulbecco's modified Eagle's medium (DMEM) supplemented with $10 \%$ fetal bovine serum (FBS) and 1\% penicillin-streptomycin (Gibco, Grand Island, NY, USA).

\section{Sample Preparation}

Fucoidan ( $85 \%$ sulfated polysaccharide) purchased from Heawon Biotech, Inc. was dissolved in PBS and prepared with the final dose of 10,50 and $100 \mu \mathrm{g} / \mathrm{ml}$ for SRB assay. For blood count, fucoidan was prepared with the final dose of $100 \mathrm{mg} / \mathrm{kg}$, and injected intraperitoneally before irradiation. 


\section{In Vitro Radio-Protection Assay}

For radio-protection, $1 \times 10^{6}$ cells/ml of HS68 cells, were plated at 4 well plates and incubated for 24 hours. After the incubation, cells were exposed either in the presence or absence of 10, 50 and $100 \mu \mathrm{g} / \mathrm{ml}$ fucoidan for 48 hours before irradiation at the dose of $8 \mathrm{~Gy}$ (Cs 137). After the irradiation, media were immediately changed to the fresh media and the exchange of media was carried out every three days. The duration to repair damage by radiation was 8 days. Cell survival was determined by the SRB assay [9].

\section{Blood Counts}

These were performed with non-tumor bearing Balb/c mice (male) [10]. Blood samples were taken from the retroorbital plexus and counted with a coulter counter. The blood count level was expressed as the percentage of the normal count determined -1 day before irradiation. The absolute values for the blood counts in normal mice were as follow: thrombocytes, $800,000-1,100,000 / \mathrm{m}^{3}$; erythrocytes, (7.0-7.4) $\times 10^{6} / \mathrm{mm} 3$, leukocytes, $9,000-10,000 / \mathrm{mm}^{3}$, hematocrit, 80 $88 \%$. Before this main test, the $\mathrm{LD}_{50}$ value on $\gamma$-irradiated $\mathrm{Blab} / \mathrm{c}$ mice was exhibited at $16 \mathrm{~Gy}$ in our primary test to find out optimal test dose. As a result, the optimal dose of radiation was determined by $8 \mathrm{~Gy}$ as half dose of $\mathrm{LD}_{50}$ value.

\section{Statistical Analysis}

The data were presented as mean \pm S.E.M., with statistical significance defined as $\mathrm{p}<0.05$ by ANOVA or the Bonferroni Multiple comparison method (SYSTAT 10.0, SPSS Inc. USA),

\section{RESULTS}

\section{In Vitro Radio-Protective Effect of Fucoidan}

In vitro radio-protective effect was exhibited by survival rate. The radiation-induced damage was exhibited varying extent on skin fibroblast cell line HS68. The survival rate of HS68 was $38 \%$ at the dose 8 Gy (Fig. 1). All tested doses of fucoidan had no effects on the growth of HS68 cells. Fucoidan affected the recovery of radiation-induced damages at all tested doses. The effect was slightly increased dosedependently. The survival rate of HS68 cells by pretreatment with fucoidan was increased by 2 times more than

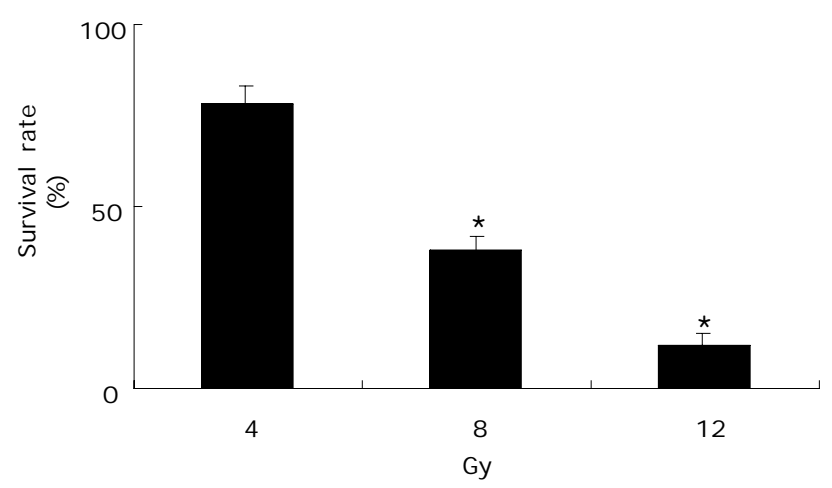

Fig. (1). Change of growth inhibition on HS68 cells treated with $\gamma$ irradiation. Data are mean \pm S.E.M. from 6 mice in each group. Statistical significance of differences between groups was assessed by one-way ANOVA followed by Boneferroni multiple comparison test $(\star \mathrm{p}<0.05)$. it's compared with radiation alone at 50 and $100 \mu \mathrm{g} / \mathrm{ml}$ (Table 1).

Table1. Change of the Survival Rate of HS68 Cells by the Absence or Presence of Fucoidan

\begin{tabular}{|c|c|c|}
\hline Irradiation $(\mathbf{G y})$ & Fucoidan $(\boldsymbol{\mu g} / \mathbf{m l})$ & Survival Rate (\%) \\
\hline \hline 8 & 0 & $36 \pm 4^{*}$ \\
\hline- & 10 & $94 \pm 2$ \\
\hline- & 50 & $95 \pm 3^{*}$ \\
\hline- & 100 & $92 \pm 4^{*}$ \\
\hline 8 & 10 & $59 \pm 6^{*}$ \\
\hline 8 & 50 & $72 \pm 3^{*}$ \\
\hline 8 & 100 & $82 \pm 5^{*}$ \\
\hline
\end{tabular}

Survival rate analysis of data from 5 experiments per group; data is mean \pm S.E.M. ( ${ }^{*} \mathrm{p}$ $<0.05)$.

\section{Hematological Change}

As can be seen in Fig. (2A), fucoidan reduced the radiation-induced fall of peripheral blood thrombocyte count, but to varying extent. Fucoidan alone had no significant effect on blood counts as compared with normal group. On day 14, when the thrombocyte of the irradiated controls had fallen to $35 \%$ compared to the initial values, the thrombocyte counts in fucoidan pre-treated group were recovered to $49 \%$. Fig. (2B) illustrates that hematocrit fell in the irradiated controls reaching a minimum value at day 9 and 14. Hematocrit level of fucoidan pre-treated group showed the recovery activity by $72 \%$, while hematocrit level of irradiated mice without fucoidan fell to $61 \%$. In case of erythrocyte level, the radiated controls were consistently maintained by the end of experiment at the range of $60 \sim 70 \%$, on the other hand, the erythrocyte counts of fucoidan pre-treated group gently increased the level of erythrocyte at the range of $82 \sim 90 \%$ (Fig. 2C). A similar protection for thrombocytes was also observed in leukocytes. The damage of thrombocytes and leukocytes by irradiation was exhibited somewhat serious than other blood counts during the experiment. After 14 days, the damage of thrombocytes was gradually repaired, however, leukocytes were not repaired till the end of the experiment even if fucoidan recovered the level of leukocyte counts by over $50 \%$ (Fig. 2D). As a result, on day 29, three blood counts except leukocytes were markedly protected from the damage of irradiation.

\section{DISCUSSION}

The ionizing radiation has been used in potential applications in medicine such as radio-therapeutics, radiology and nuclear medicine for a long time, on the other hand many people like operators and patients are exposed to ionizing radiation situations. The radiation passing through living tissues generates reactive free radicals. These free radicals can interact with critical macromolecules such as DNA, proteins and membranes and can bring about cell damage, and lead to cell biological dysfunction and death. With regards to side effects of ionizing radiation, it is imperative to protect humans from radiation-induced genotoxicity or lethality 

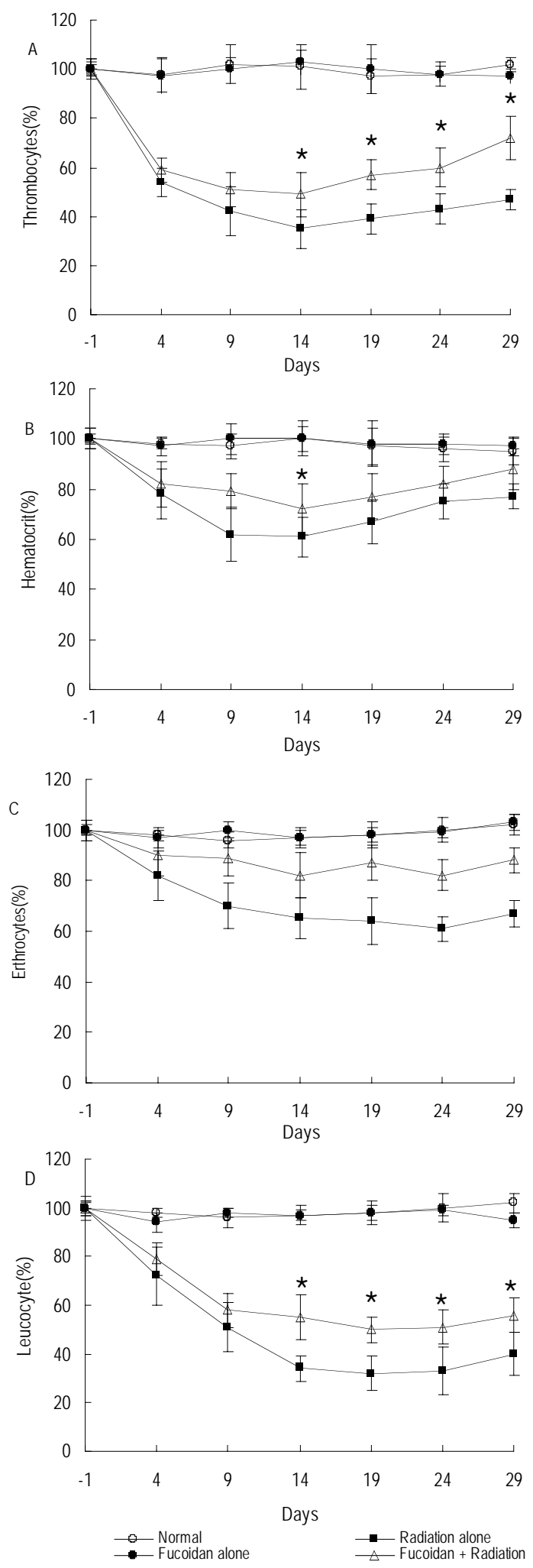

Fig. (2). Change of growth inhibition on HS68 cells treated with $\gamma$ irradiation. Data are mean \pm S.E.M. from 6 mice in each group. Statistical significance of differences between groups was assessed by one-way ANOVA followed by Boneferroni multiple comparison test $(\star p<0.05)$.

[11]. General biological aspects of radioprotective agents has shown two main functions as radical scavenging effects and immunostimulating effects [12-14]. First class of radioprotective agents is thiol compounds with mainly radical scavenging properties, that are used as radioprotective agents and they reduced mortality induced by lethal dose of gamma irradiation [2,6]. Amifostine is a useful radioprotective agent in this field approved by FDA as radioprotective agent for preventing xerostomia induced by gamma irradiation in patients under radiotherapy [15]. Although thiol compounds have good efficacy in radioprotection, these compounds have side effects when administered to humans, leading to adverse toxic effects such as hypotension, nausea, vomiting and allergy [6]. Immunostimulating compounds increase proliferation and production of bone marrow cells, reduced by ionizing irradiation. With regards to low toxicity of natural products, many researchers have focused on natural products to find lead compounds with potential radioprotective effects such as melatonin, silymarin, vitamin C, vitamin E and selenium [16-19].

Fucoidan is a polysaccharide purified from the brown seaweed such as Fucus vesiculosus and Laminaria japonica. Fucoidan has been shown as a potential antioxidant in various researches for a long time. The correlation between the sulfate content and scavenging superoxide radical ability was positive [20]. This correlation was also found in recent studies in which fucoidan reduces $\mathrm{CCl}_{4}$-induced liver injury and cellular and neurotoxic effects [21-23].

This study showed that fucoidan protected the radiationinduced damage, such as the decrease of cell viability on HS67 cell line and the change of hematological parameters on Balb/c mice, however, it is still not clear how to protect the damage when they receive the radiation. However, fucoidan has the potential antioxidant activity as a radical scavenger well known through various researches. Therefore, our findings indicated that fucoidan-treated HS68 cells and blood cells from Blab/c mice have an increased viability through the scavenging activity of fucoidan from the characteristic of sulfate-rich structure.

\section{ACKNOWLEDGEMENT}

This work was supported by the Korea Institute of radiological and Medical sciences (KIRAMS) through the Korea Science and Engineering Foundation (KOSEF).

\section{REFERENCES}

[1] Cairnie, A.B. Radiat. Res., 1983, 94, 221.

[2] Floersheim, G.L.; Bieri, A. Br. J. Radiol., 1990, 63, 468.

[3] Yuhas, J.M.; Spellmann, J.M.; Culo, F. Cancer Clin. Trials, 1980, 3, 211.

[4] Devi, P.U.; Ganasoundari, A. Indian J. Exp. Biol., 1995, 33, 205.

[5] Ganasoundari, A.; Devi, P.U.; Rao, M.N. Mutat. Res., 1997, 373, 271.

[6] Turrisi, A.T.; Kligermann, M.N.; Glover, D.J.; Glick, J.H.; Norfleet, L.; Gramkowski, M. In: Nygaard, O.F.; Simic, M.G., Eds.; Radioprotectors and anticarcinogens, Academic Press: London, 1983, pp. 681-694.

[7] Chizhov, A.O.; Dell, A.; Morris, H.R.; Haslam, S.M.; McDowell, R.A.; Shashkov, A.S.; Nifant'ev, N.E.; Khatuntseva, E.A.; Usov, A.I. Carbohydr. Res., 1999, 320, 108.

[8] Moon, H.J.; Lee, S.R.; Shim, S.N.; Jeong, S.H.; Stonik, V.A.; Rasskazov, V.A.; Zvyaginsteva, T.; Lee, Y.H. Biol. Pharm. Bull., 2008, 31, 284.

[9] Skehan, P.; Storeng, R.; Scudiero, D.; Monks, A.; McMahon, J.; Vistica, D.; Warren, T.J.; Bokesch, H.; Kenney, S.; Boyd, M.R. J. Natl. Cancer Inst., 1990, 82, 1107. 
[10] Floersheim, G.L.; Chiodett, N.; Bieri, A. Br. J. Radiol., 1988, 61, 501.

[11] Hosseinimehr, S.J. Drug Discov. Today, 2007, 12, 794.

[12] Weiss, J.F.; Landauer, M.R. Toxicology, 2003, 189, 1.

[13] Rubin, P.; Johnston, C.J.; Williams, J.P.; McDonald, S.; Finkelstein, J.N. Int. J. Radiat. Oncol. Biol. Phys., 1995, 33, 99.

[14] Johnston, C.J.; Piedboeuf, B.; Rubin, P.; Williams, J.P.; Baggs, R.; Finkelstein, J.N. Radiat. Res., 1996, 145, 762.

[15] Budd, G.T.; Lorenzi, V.; Ganapathi, R.; Adelstein, D.; Pelley, R.; Olencki, T.; McLain, D.; Bukowski, R.M. Support Care Cancer, 1994, $2,380$.

[16] Shirazi, A.; Ghobadi, G.; Ghazi-Khansari, M.A. J. Radiat. Res., $\mathbf{2 0 0 7}, 48,263$.

[17] Ramadan, L.A.; Roushdy, H.M.; Abu Senna, G.M.; Amin, N.E.; El-Deshw, O.A. Pharmacol. Res., 2002, 45, 447.
[18] Cai, L.; Koropatnick, J.; Cherian, M.G. Chem. Biol. Interact., 2001, $137,75$.

[19] Kumar, K.S.; Srinivasan, V.; Toles, R.; Jobe, L.; Seed, T.M. Mil. Med., 2002, 167, 57.

[20] Wang, J.; Zhang, Q.; Zhang, Z.; Li, Z. Int. J. Biol. Macromol., 2008, $42,127$.

[21] Kang, K.S.; Kim, I.D.; Kwon, R.H.; Lee, J.Y.; Kang, J.S.; Ha, B.J. Arch. Pharm. Res., 2008, 31, 622.

[22] Nakamura, T.; Suzuki, H.; Wada, Y.; Kodama, T.; Doi, T. Biochem. Biophys. Res. Commun., 2006, 343, 286.

[23] Jhamandas, J.H.; Wie, M.B.; Harris, K.; MacTavish, D.; Kar, S. Eur. J. Neurosci., 2005, 21, 2649.

Received: October 17, 2008

Revised: January 09, 2009

Accepted: February 11, 2009

(C) Lee et al.; Licensee Bentham Open.

This is an open access article licensed under the terms of the Creative Commons Attribution Non-Commercial License (http://creativecommons.org/licenses/by-nc/3.0/) which permits unrestricted, non-commercial use, distribution and reproduction in any medium, provided the work is properly cited. 